\title{
Amlodipine-induced gingival hyperplasia
}

\author{
Ardeshir Lafzi ${ }^{1}$, Ramin Mostofi Zadeh Farahani ${ }^{2}$, Mohammadali Mohajel Shoja ${ }^{3}$ \\ (1) (DDS, MSc). Associate professor, department of periodontics, School of dentistry \\ (2) (DDS). Research assisstant, School of dentistry \\ (3) (MD). School of Medicine. Tabriz University of Medical Sciences, Tabriz, Iran
}

Correspondence:

Dr. Ramin Mostofi Zadeh Farahani

School of Dentistry, Tabriz University of Medical Sciences,

Golgasht Avenue, Tabriz, East Azarbaijan, Iran.

E-mail:r.mostofi@gmail.com

Received: 15-03-2006

Accepted: 16-06-2006

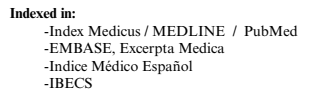

-Indice M

Lafzi A, Farahani RMZ, Shoja MAM. Amlodipine-induced gingival hyperplasia. Med Oral Patol Oral Cir Bucal 2006;11:E480-2.

O Medicina Oral S. L. C.I.F. B 96689336 - ISSN 1698-6946

\begin{abstract}
Drug-induced gingival hyperplasia is a serious concern both for the patient and the clinician. A 45 year-old Caucasian male patient with hypertension, who received amlodipine $(10 \mathrm{mg} / \mathrm{day}$, single dose orally) for two months, sought medical attention because of the new-onset gingival enlargement. On clinical examination a generalized and firm overgrowth of the gingival throughout the maxilla and the mandible were evident. The lack of gingival inflammation and purulent discharge were other features of the clinical scenario. Histological assessment of the biopsy specimen revealed the hyperplasia of connective tissue, epithelial acanthosis, and elongated rete ridges along with few inflammatory cells. The histological and the clinical evidences were consistent with amlodipine-induced gingival hyperplasia. We believe that the present report indicates the most rapidly developed case of amlodipine-induced gingival hyperplasia reported to date. The related literature is reviewed and the underlying pathogenic mechanisms of this rare side-effect are discussed here.
\end{abstract}

Key words: Gingival hyperplasia, Amlodipine, pocket/pseudopocket assembly.

\section{INTRODUCTION}

Gingival hyperplasia due to the concomitant unesthetic appearance and the formation of new niches for the periopathogenic bacteria (1) is considered a serious adverse drug reaction. Acanthosis of epithelial lining, elongation of rete ridges, and sparse fibroblasts in a dense collagenous matrix are the underlying histological changes. Three main classes of drugs known to cause $\mathrm{GH}$ are anticonvulsants (2), antihypertensive calcium antagonists (3) and the immunosuppressant cyclosporine (4). Despite the relatively high prevalence of nifedipine-induced gingival hyperplasia (3), amlodipine has rarely been reported as the potential etiologic cause of gingival hyperplasia $(3,5,6)$. We presented a rare case of amlodipine-induced gingival hyperplasia along with the review of relevant literature.

\section{CASE REPORT}

A 45 year-old Caucasian male patient referred to the department of periodontics at Tabriz University of Medical Sciences complaining of "swollen gums". Past medical history was remarkable for a newly-diagnosed hyperten- sion for which the patient received amlodipine $(10 \mathrm{mg} / \mathrm{day}$, single dose orally) for the last two months. The patient had noted a gradual and painless enlargement of the gingiva of three weeks duration. Physical examination revealed a young man who was well-doing and in no acute distress. A generalized and firm overgrowth of the gingiva was found throughout the maxilla and mandible particularly at the buccal side (Fig. 1). The lack of periodontal pockets (mean probing depth: $2.4 \mathrm{~mm}, \mathrm{SD}: 1.2$ ) was a prominent feature of gingival overgrowth indicating an outward rather than vertical enlargement of gingiva. No changes in the gingival color, purulent discharge and bleeding on probing were detected which were in accordance with the lack of the gingival inflammation. Examination was otherwise unremarkable. Microscopic inspection of the gingival biopsy specimens demonstrated a connective tissue hyperplasia, acanthosis of overlying epithelium, and elongated rete ridges together with few sparse inflammatory cells. The lesion was diagnosed as amlodipine-induced gingival hyperplasia based on clinical and histological evidences. 


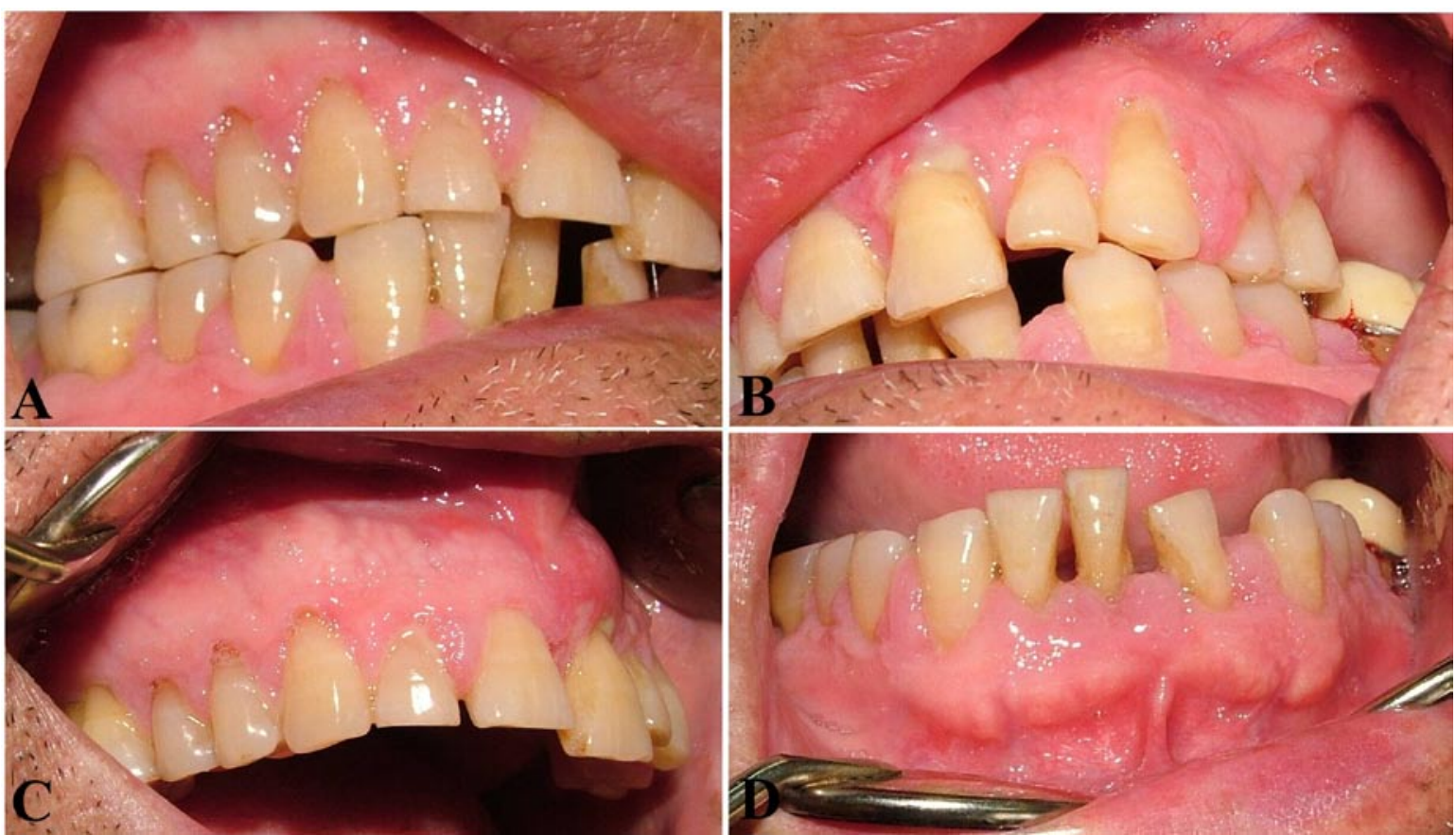

Fig. 1. Clinical presentation of gingival hyperplasia. Figures A and B show the left and right sides, respectively. Figures C and D are the maxillary and mandibular views, respectively.

\section{DISCUSION}

Gingival hyperplasia with its potential cosmetic implications and also providing new niches for the growth of microorganisms is a serious concern for both the patients and clinician. Calcium channel blockers are considered potential etiologic agents of drug-induced gingival hyperplasia. Although the incidence of nifedipine-induced gingival hyperplasia is about $10 \%$ (3), very few reports of amlodipine-related gingival hyperplasia does exist in the extant literature $(3,5,6)$. In a series of 150 cardiac patients, it was found that amlodipine at a dose of $5 \mathrm{mg} /$ day can not induce gingival hyperplasia even if taken more than 6 months (6). Contrarily, Seymour et al. reported three patients with poor periodontal conditions who developed gingival hyperplasia upon a chronic usage (at least three moths) of amlodipine (3). Our patient had a favorable oral condition and received a rather low-dose of amlodipine for only two months. We believe that the present report indicates the most rapid-onset case of amlodipine-induced gingival hyperplasia reported to date.

The underlying mechanism remains to be fully understood. However, two main inflammatory and non-inflammatory pathways have already been suggested. The proposed non-inflammatory mechanisms include defective collagenase activity due to decreased uptake of folic acid (7), blockage of aldosterone synthesis in adrenal cortex and consequent feedback increase in ACTH level (8), and upregulation of keratinocyte growth factor (KGF) (9). Alternatively, inflammation may develop as a result of direct toxic effects of concentrated drug in crevicular gingival fluid (CGF) and/or bacterial plaques (10). This inflammation could lead to the upregulation of several cytokine factors such as TGF-B1 (11).
In the present case the lack of inflammatory component parallels the absence of vertical gingival growth and consequently the lack of periodontal pockets or pseudopockets. We hypothesize that the formation of pocket/pseudopocket assembly is a phenomenon that is associated with gingival inflammation. So that, TGF- $B 1$ and other factors responsible for the production of a fibrous scaffold may be essential for the vertical growth of gingiva - pseudopocket developmentand also the formation of periodontal pockets necessitates the inflammatory degradation of the periodontal tissues. As an alternative, periodontal pocket formation may precede the inflammation.

Finally, we emphasize that gingival hyperplasia could be a side effect of amlodipine even with a very short term and low dose administration. 


\section{REFERENCES}

1. Takada K, Sugiyama H, Umezawa K, Mega J, Hirasawa M. The subgingival microflora in phenytoin-induced gingival hyperplasia. J Periodontal Res 2003;38:477-81.

2. Cebrian JL, Chamorro M, Arias J, Gomez E. Extreme phenytoininduced gingival hyperplasia. Presentation of two cases. Med Oral 1998;3:237-40.

3. Seymour RA, Ellis JS, Thomson JM, Monkman S, Idle JR. Amlodipineinduced gingival overgrowth. J Clin Periodontol 1994;21:281-3.

4. Eggerath J, English H, Leichter JW. Drug-associated gingival enlargement: case report and review of aetiology, management and evidence-based outcomes of treatment. J N Z Soc Periodontol 2005;88:7-14.

5. Ellis JS, Seymour RA, Thomason JM, Monkman SC, Idle JR. Gingival sequestration of amlodipine and amlodipine-induced gingival overgrowth. Lancet 1993;341:1102-3.

6. Jorgensen MG. Prevalence of Amlodipine-related gingival hyperplasia. J Periodontol 1997;68:676-8.

7. Brown RS, Sein P, Corio R, Bottomley WK. Nitrendipine-induced gingival hyperplasia. Oral Surg Oral Med Oral Pathol 1990;70:593-6.

8. Nyska A, Shemesh M, Tal H, Dayan D. Gingival hyperplasia induced by calcium-channel blockers: mode of action. Med Hypotheses 1994; 43:115-8.

9. Das SJ, Olsen I. keratinocyte growth factor is upregulated by hyperplasia-inducing drug nifedipine. Cytokine 2000; 12:1566-9.

10. van der Vleuten CJ, Trijbels-Smeulders MA, van de Kerkhof PC. Telangiectasia and gingival hyperplasia as side-effects of amlodipine (Norvasc) in a 3-year-old girl. Acta Derm Venereol 1999;79:323-4.

11. Border WA, Noble NA. Transforming growth factor beta in tissue fibrosis. N Engl J Med 1994;331:1286-92. 